\title{
Análise comportamental do discurso: uma entrevista com uma paciente oncológica
}

\section{Behavioral analysis of discourse: A interview with an oncological patient}

\author{
Elizeu Borloti ${ }^{1}$, Verônica Bender Haydu², Renatha El Rafihi-Ferreira ${ }^{3}$ e Silvia Aparecida Fornazari ${ }^{4}$
}

\begin{abstract}
[1] Universidade Federal do Espírito Santo [2] Universidade Estadual de Londrina | Apoio: Bolsa produtividade em pesquisa da Fundação Araucária [3] Universidade de São Paulo [4] Universidade Estadual de Londrina Título abreviado: Análise comportamental do discurso I Endereço para correspondência: Universidade Federal do Espírito Santo, Departamento de Psicologia Social e do Desenvolvimento. Avenida Fernando Ferrari, 514, Goiabeiras, Vitória, ES. CEP: 29075-910 I Email: borloti@hotmail.com
\end{abstract}

Resumo: Análise Comportamental do Discurso (ACD) é um método interpretativo da função de um conjunto de comportamentos verbais. Para desenvolver uma ACD, a análise dos elementos de segmentos verbais de uma entrevista com uma paciente oncológica complementou-se com as ações de: discriminar-interpretar ocorrências de sentenças-argumento e de seus eventos antecedentes e consequentes; reinterpretá-las para encontrar exemplos que confirmem a regularidade de certas funções; fazer uma descrição funcional da interpretação e auto-descrever funcionalmente o interpretar. Observou-se a ocorrência frequente de unidades autoclíticas que exacerbaram a função das respostas que elas acompanharam, na mesma direção da "intenção" do discurso: aumentar o poder de convencimento. Observou-se o controle múltiplo do discurso e, por isso, o acesso a todas as variáveis que o controlaram foi uma dificuldade na sua análise.

Palavras-chave: Análise do discurso, Comportamento verbal, Autoclítico, Fé religiosa; Análise funcional

Abstract: Behavioral Discourse Analysis (BDA) is an interpretative method of the function of a set of verbal behaviors. To develop an BDA, the analysis of the elements of verbal segments of an interview with a cancer patient ware supplemented with actions of: to interpretdiscriminate instances of sentences-argument and their antecedents and consequences; to reinterpret them to find examples that confirm the correctness of certain functions; to do a functional description of interpretation; and to self-descript the function of the interpretation. It was observed a frequent occurrence of autoclitic unities which exacerbated the function of responses that they accompanied, to the same direction of the "intention" of the discourse: to increase the convincing power. It was observed the multiple control of the discourse and, so that, the access to all the variables that control it was a difficulty in its analysis.

Key words: Discourse analysis, Verbal behavior, Autoclitic, Religious faith, Functional analysis 
A compreensão das relações verbais em práticas culturais precisa ser desenvolvida (Glenn, 1989). $\mathrm{Na}$ prática clínica da psicoterapia, por exemplo, é necessária a análise das interações entre o cliente e o terapeuta (as quais, em grande parte, são interações verbais) para que as modificações comportamentais dos clientes, devidas à intervenção do terapeuta, possam ser esclarecidas. Portanto, na clínica e nas demais práticas culturais, uma abordagem descritiva baseada na análise comportamental do discurso (ACD) pode vir se tornar uma metodologia de análise que viabilizará a compreensão de uma parte do processo verbal componente dessas práticas. Nelas, discursos mostram ideologias (Glenn, 1989), crenças e atitudes (afirmações verbais de probabilidade de eventos ocorrerem e de preferência pela ocorrência dessa probabilidade, respectivamente; Guerin, 1994) que, por sua vez, ajudam a mantê-las. A ACD está sendo considerada empiricamente neste artigo como foi proposta teoricamente por Borloti, Iglesias, Dalvi e Silva (2008): uma análise que combina a hermenêutica comportamental (Dougher, 1993) com a análise de segmentos (categorias) de comportamento verbal (Skinner, 1957).

A ACD é uma das formas, dentre muitas, de se fazer análise do discurso (AD) (Borloti et al., 2008). Segundo Gill (2002), existem pelo menos 57 formas de se fazer $\mathrm{AD}$, as quais variam de acordo com a sua base teórica. Por exemplo, de acordo com a AD de base foulcaultiana, ao se fazer uma análise de discurso, analisa-se "(...) um conjunto de regras anônimas, históricas, sempre determinadas no tempo e no espaço que definiram em uma época dada, e para uma área social, econômica, geográfica ou linguística dada, as condições da função enunciativa" (Foulcault, 1971/1973, p. 97). A ACD se diferencia das demais formas de AD por ser um método interpretativo da função de um conjunto de operantes verbais (o discurso). Esse método é baseado em princípios do comportamento verbal, fundamentados no Behaviorismo Radical de Skinner (1957), principalmente na concepção de que as interações verbais são comportamentos operantes. "O comportamento verbal é modelado e mantido por um ambiente verbal - por pessoas que respondem ao comportamento de certo modo por causa das práticas do grupo do qual são parte." (Skinner, 1957, p. 226).
A especificidade do comportamento verbal é a mediação do reforço feita por um ouvinte especialmente treinado por uma comunidade verbal para reforçar o comportamento do falante. A interação entre o falante e o ouvinte - episódio verbal - constitui uma relação entre o ambiente social (ouvinte) e um ser humano (falante) numa prática cultural. Assim, o ouvinte é a audiência que faz a mediação do reforço, exercendo a função discriminativa para a emissão da resposta verbal; na presença de uma audiência a resposta verbal é emitida e reforçada. Ouvintes compõem a comunidade verbal, que evolui a partir das mudanças nas práticas dessa comunidade. Essas práticas constituem o ambiente verbal tradicionalmente chamado de "linguagem" (Skinner, 1986). Nesse contexto, ocorrem os episódios verbais, caracterizados como relações entre falante e ouvinte. Assim, o comportamento verbal é o produto da evolução desse ambiente verbal (Skinner, 1987), sendo resultado do entrelaçamento dos três tipos de contingências envolvidas na seleção por consequências (a seleção natural, a ontogenética e a cultural), assumindo função adaptativa ao ser modelado e mantido por suas consequências.

"O discurso é inferido de um conjunto de operantes verbais com certas propriedades (encadeamento, intensidade, etc.)" (Borloti et al., 2008, p. 103). Esse conjunto se unifica a partir de uma consequência comum sobre o comportamento de um ouvinte que pertence a uma comunidade verbal (ou aos "coletivos" ou "subgrupos", em algumas das denominações teóricas de cientistas sociais). A ACD, portanto, atenta para a função desses operantes verbais, buscando identificar as variáveis que os controlam em combinação, especialmente, a audiência sobre a qual, o discurso emitido produz suas consequências. Nos termos dos teóricos da AD tradicional, a linguagem é como uma ação "para fazer coisas" (Gracia, 2004, p. 47). Assim, quando se faz a ACD, se analisa, indubitavelmente, o comportamento verbal de falantes e ouvintes, considerando os estímulos auditivos (verbalizações) ou visuais (transcrições de verbalizações ou textos) que fazem parte dos controles de interações em episódios verbais. O fazer a ACD é também uma interação em um episódio verbal e quem a faz deve se posicionar como ouvinte de quem discursa.

O ouvinte é tão importante no episódio verbal 
que Skinner (1957) considerou-o como um controle especial. Sua primeira função é a de fonte de reforço ao comportamento do falante e a segunda, é a de audiência com função discriminativa, uma vez que esse reforço ocorre sempre em uma dada situação contextual (ocorre, inicialmente, em contingências com a presença de uma audiência física e, a partir dessa situação, pode ocorrer na presença de audiência generalizada e também sem a presença de uma audiência física, como no caso das extensões do mando a ouvintes mortos, deuses, objetos inanimados etc.). Assim, a presença da audiência aumenta ou diminui a probabilidade de emissão do comportamento verbal. Skinner referiu-se a esse fato da seguinte forma: "uma audiência é, comumente, uma condição para o reforço de um amplo grupo de respostas e, portanto, afeta a força de tal grupo. Diferentes audiências controlam diferentes subdivisões do repertório do falante" (p. 173). Tais subdivisões podem definir temas, assuntos ou tópicos como uma propriedade básica de um discurso, que podem ser suas partes ou o seu todo. Apesar de $o$ assunto estar sob controle da função discriminativa, a importância desse controle na evocação do comportamento verbal, tanto nas conversações cotidianas quanto nas alocuções ou nos textos formais, levou Skinner a afirmar que "a seleção do assunto" (e, adicionando, a seleção da forma de apresentá-lo ao ouvinte) constitui a "terceira função da audiência" (p. 175).

Antecedentes verbais ou não verbais e consequências específicas ou generalizadas podem exercer controle combinado sobre o discurso de uma maneira complexa. Ao se fazer a ACD, se busca identificar esses antecedentes e consequentes, incluindo os possíveis sentidos dessas variáveis na história individual e cultural de quem discursa, de modo a se ter acesso às relações de controle que estabeleceram e mantiveram o discurso (Passos, 2003). Antecedentes, consequentes e respostas verbais estabelecem relações de contingências (em geral, múltiplas). A partir dessas relações, podem ser identificadas oito categorias de operantes verbais: mando, tato, ecóico, cópia, ditado, textual, intraverbal e autoclítico (Skinner, 1957). Diferentes condições antecedentes são identificadas para diferenciar essas categorias verbais: estímulos discriminativos não verbais, no caso do tato; estímulos discrimina- tivos verbais, nos casos do intraverbal, do ecóico, do textual e da transcrição; e operações de privação e de estimulação aversiva, no caso do mando. Os eventos consequentes podem ser reações imediatas ou longínquas do ouvinte (e.g., reação emocional; fazer o que se pede; aprovação ou concordância com o que se diz). O ouvinte pode estar fisicamente presente ou não (ou ser o próprio falante), e a consequência pode ser específica ou generalizada, como quando se emite um discurso que se sabe ser "coerente" ou "ético".

Para classificar as relações verbais que se combinam no discurso é necessário identificar seus antecedentes (estímulos discriminativos e operações estabelecedoras) e consequentes (estímulos reforçadores específicos ou generalizados). As relações verbais combinadas e imprescindíveis na análise do discurso são: o mando, o tato, o intraverbal (operantes essenciais ou primários) e o autoclítico (operantes secundários) (Borloti et al., 2008).

O mando é controlado por operações estabelecedoras que, advindas do ambiente físico ou do ouvinte, atuam sobre o falante estabelecendo estados do tipo privação ou estimulação aversiva. Desculpas, juramentos, advertências, convencimentos e tantas classes operantes focalizadas pelos pesquisadores da vertente teórica dos "atos de fala" da $\mathrm{AD}$ tradicional são exemplos de mandos controlados por operações estabelecedoras advindas do ouvinte.

Tatos são respostas verbais controladas por estímulos antecedentes não verbais mantidos por reforços generalizados liberados pela comunidade verbal. "Objetos sociais" (e suas propriedades, por exemplo, a "negatividade" de uma doença, sentida pelo doente) tratados pelos pesquisadores da vertente teórica das "representações sociais" são exemplos de estímulos que controlam tatos (ou intraverbais emitidos como se fossem tatos, estabelecidos por uma história de reforço pelo convencimento do ouvinte; Guerin, 1994).

Intraverbais são operantes verbais caracterizados como relações entre estímulos necessariamente verbais e respostas. Os estímulos verbais são produtos do comportamento verbal que, como unidades capazes de afetar receptores sensoriais do falante, têm efetividade controladora sobre respostas verbais (Peterson, 1978), podendo, portanto, serem 
produzidos por quaisquer modalidades de "palavras": ouvidas, lidas (ou pensadas), ou visualizadas em gestos (Catania, 1998). A arbitrariedade reforçada na relação intraverbal é convencional (por exemplo, 1-2-3) ou não, e é formal ou informalmente condicionada (i.e., condicionada em práticas culturais formais, como a educação, ou em interações sociais informais; Vargas, 1986).

Os autoclíticos são relações verbais secundárias sob controle de propriedades de composição, de criação, de avaliação, de direção, de seleção, de organização e de produção do discurso, sendo emitidas de modo dependente e concorrente com os demais operantes primários, especialmente, na fala contínua, com mandos, tatos e/ou intraverbais. Podem ser unidades lexicais (e.g., artigos, preposições) ou não (e.g., a inflexão da ironia) e dependem de (e alteram a função dos) operantes verbais primários. Com o autoclítico, o discurso é manipulado, produzido, editado, criado, etc.

Para classificar as relações verbais nas categorias funcionais de Skinner (1957), devem ser considerados os vários aspectos do ambiente com os quais o falante que emite o discurso interage. Devem ser incluídos nessa análise o controle que pode fundir relações de tato e de mando e relações desses com os intraverbais ou com as estratégias de estilo de convencimento do ouvinte, que fazem com que intraverbais pareçam tatos (Guerin, 1992). Para cumprir essa tarefa, é necessário um procedimento que atente para as variáveis que controlam o discurso, para assim identificar a função que ele exerce como um conjunto de operantes. Um procedimento proposto por analistas do comportamento (Borloti et al., 2008) para realizar esse tipo de análise é a ACD, que considera a relação entre o contexto e o significado: a história e o ambiente produzem o significado para os eventos contemporâneos. Assim, a ACD combina a hermenêutica comportamental (Dougher, 1993) com a análise de segmentos de comportamento verbal (Skinner, 1957).

Borloti et al. (2008) enfatizam o cerne da ACD a partir da proposta de Skinner (1957, p. 452): "quando estudamos [discursos], estudamos os efeitos [dos discursos] sobre nós. É o nosso comportamento em relação a tais [discursos] o que nós observamos". Com isto, a ACD propõe que analisar um discurso inclui analisar o comportamento verbal do analista sob o controle de tal discurso. Portanto, é um processo verbal dependente das práticas do grupo que o mantém; e que modela a experiência de quem falou e de quem fala agora sobre o que foi falado. Assim, em termos funcionais, considera-se a sentença emitida pelo falante como sendo um estímulo discriminativo verbal, que tem a função de orientar o comportamento do ouvinte - o analista comportamental do discurso - diante de uma relação de contingência (Place, 1998). Essa relação de contingência envolve o comportamento do falante na interação com os estímulos não verbais e/ou verbais do contexto em que os membros da interação estão inseridos. Uma sentença pode ser um argumento, que é definido como uma proposição: "um comportamento verbal complexo que engloba tatos e intraverbais modificados por autoclíticos particulares" (Terrell \& Johnson, 1989, p. 36). Portanto, os operantes de uma proposição também podem produzir as duas consequências básicas da argumentação como efeitos unificados: a persuasão (o ouvinte se emociona) e o convencimento (o ouvinte pensa como o falante) (Abreu, 2009).

A estimulação visual da argumentação, controlando o comportamento textual do analista comportamental do discurso, é considerada como uma sentença-argumento (S-A) que tem sua função de estímulo discriminativo verbal (para o comportamento textual do analista) fundida pelas funções das relações verbais contidas na proposição/argumentação. Segundo Terrel e Johnson, essas funções podem ser de tato ou de intraverbal, sempre modificadas pela função autoclítica (entretanto, dado o controle múltiplo, a função mando também pode estar presente); e podem aparecer no argumento central ou nos argumentos adicionais. Argumento central é uma proposição da qual se infere um controle por regra que é fundamental para o posicionamento verbal do falante acerca de um tópico, mantendo-se consistente em todo o seu discurso (Reese, 1989); os argumentos adicionais são emissões de operantes verbais com a função de reforçar as variáveis de controle (em geral, intraverbais) do argumento central (Pimentel, 2009). Dadas essas características, as S-A's, como segmentos compostos por operantes essenciais (i.e., operantes verbais primários ou de primeira ordem) e elos intraverbais modificados por autoclíticos (Skinner, 1957), 
podem ser submetidas às etapas da hermenêutica comportamental sugeridas por Dougher (1993) que consistem em (após transcrito o dado verbal):

1) ler diversas vezes o registro das ocorrências de S-A's e de antecedentes e consequentes (cujas funções interdependentes são inferidas de suas relações, por exemplo, para mando o antecedente é uma operação estabelecedora e o consequente, um reforço específico);

2) reinterpretar o dado para encontrar exemplos que confirmem a regularidade de certas funções interpretadas;

3) buscar compreender o que foi escrito a partir do próprio escrever, ao fazer a análise do discurso (Skinner, 1957, exemplifica isso dizendo que interpretar o comportamento de Shakespeare e Júlio César é a análise dos controles desse interpretar);

4) confirmar as respostas discriminativas emitidas pelo analista e identificar as razões pelas quais foram feitas, reafirmando-as pela corroboração das funções dos seus antecedentes e consequentes.

A versão comportamental da experiência hermenêutica tem seis características: é intrinsecamente histórica, dialética, objetiva, controlada pelo texto, é a compreensão do que é dito no presente e em sua experiência não há um significado que é captado pelo intérprete, pois o significado é dado pela história de reforço daquele que significa, no caso, o intérprete, que é nesse momento, o falante (Saquetto \& Borloti, 2008). Na compreensão do discurso, portanto, sujeito e objeto não são vistos separadamente, uma vez que quem compreende o discurso se posiciona como quem discursa. O significado de um relato verbal para quem o analisa é identificado a partir das práticas da comunidade verbal do analista. Dessa forma, a ACD persiste na formulação de questões sobre o próprio ato de interpretar (por exemplo, "Por que eu senti que o falante está querendo me convencer? Convencer do quê?) até atingir uma interpretação da função do conjunto verbal chamado discurso (Borloti et al., 2008). Isso é relevante na análise dos componentes verbais de quaisquer práticas culturais (Glenn, 1989), incluindo seus movimentos sociais (Guerin,
1994). Num processo eleitoral, por exemplo, é possível analisar as funções verbais comuns em discursos vencedores de eleições (Borloti et al. 2008) e essa análise servir para avaliar se (e como) outros discursos são influenciados por essas funções e se (e como) afetam eleitores.

No processo terapêutico, em especial, as interações entre terapeuta e cliente durante as sessões devem produzir modificações verbais e não verbais no repertório comportamental do cliente no dia a dia dele. As interações verbais representam uma grande parte desse processo. Elas envolvem racionalização de contingências e análise lógica dessa racionalização, e isso é parte do conceito de proposição/sentença de Place (1998). Uma sentença é um estímulo discriminativo que pode atuar como regra na orientação do comportamento do ouvinte numa contingência (Place, 1998). A análise de sentenças pela $\mathrm{ACD}$, portanto, permite a inferência da probabilidade de ocorrência de comportamentos a partir da identificação desse controle por regra nas sentenças, sejam as sentenças de "atitudes" do falante (i.e., descrições de preferência, Guerin, 1994), sejam as sentenças de "crenças" (i. e., descrições de probabilidade; Guerin, 1994). Ao fazer ACD, o terapeuta pode compreender, por meio da análise de descrições de contingências (que ocorreram fora das sessões) e/ou de observações de contingências (ocorrendo dentro da sessão), o efeito de sua intervenção e, assim, planejar sessões subsequentes com esse cliente e com outros. Portanto, descrever como se faz uma ACD, considerando que ela pode vir se tornar uma metodologia que possibilitará a compreensão de uma parte do processo terapêutico, justifica o presente estudo, que tem a saúde como temática.

A ACD aqui relatada foi desenvolvida a partir dos registros fornecidos por uma das autoras do presente estudo, obtidos quando atuou como terapeuta de uma paciente oncológica. Assim, este artigo tem como objetivo descrever a aplicação do método da ACD, descrito por Borloti et al. (2008), a uma entrevista conduzida com essa paciente na qual descreve a relação de sua doença com sua fé religiosa. A questão que se formulou é se a base teórica e metodológica da ACD permite compreender os dados verbais obtidos, interpretando-os e reinterpretando-os para encontrar exemplos que 
confirmem a regularidade de certas funções de conjuntos de operantes verbais, e fazer uma descrição e uma autodescrição funcional da interpretação.

\section{Método}

\section{Participantes}

Uma paciente (chamada doravante de participante) que recebeu diagnóstico de Leucemia mielóide aguda e que, na época da entrevista, estava em fase de manutenção do tratamento oncológico; casada, possuía curso superior completo, tinha 29 anos e seguia a religião Católica (antes e depois do diagnóstico da doença). Foi contatada por intermédio de uma associação especializada em tratamento de câncer e, após esclarecimentos sobre a pesquisa, leu e assinou o Termo de Consentimento Livre e Esclarecido, aprovado pelo Comitê de Ética em Pesquisa da Universidade Paulista.

Uma entrevistadora, estudante universitária, com 23 anos de idade que cursava o quinto ano do curso de Psicologia.

\section{Instrumento}

Para a coleta de dados, foi utilizado um roteiro de entrevista com informações gerais (idade, escolaridade, estado civil, tipo de câncer, fase de tratamento e religião, anterior e posterior ao diagnóstico de câncer) e três questões abertas: 1) O que a fé representa para você? 2) A fé influenciou sua relação com a sua doença? Como? 3) Fale (escreva) a respeito de suas experiências com relação à fé. Por escolha da participante, o roteiro foi respondido de forma escrita. As questões do roteiro de entrevista foram centralizadas na temática "fé", porque a explicação de como a fé contribuiu na superação de seus problemas de saúde era um dos aspectos mais citados pela cliente durante o processo terapêutico.

\section{Procedimento}

O comportamento verbal tomado para análise foi a S-A escrita pela participante como respostas às questões da entrevista. As respostas da participante foram emitidas em um episódio verbal constituído por ela, como falante, e por um ouvinte genérico e/ou específico, a entrevistadora. O comportamento da entrevistadora foi analisado, em alguns momentos, como parte do controle de estímulo para o comportamento de interesse.

Em termos funcionais, uma sentença escrita pela participante foi definida como um estímulo discriminativo verbal visual que controlou o comportamento dos pesquisadores/analistas de interpretar uma relação de contingência diante da qual a sentença foi escrita. Formulada diante de possíveis instâncias (passadas, presentes e futuras) de contingências, uma sentença escrita orientou (como regra) tanto o comportamento verbal da participante quanto o comportamento de interpretar esse comportamento verbal (Place, 1998). Os estímulos não verbais e/ou verbais, constitutivos das questões da entrevista e/ou produzidos continuamente pelos operantes verbais emitidos por ela enquanto escrevia, também fizeram parte dessas relações de contingência.

A argumentação, controlando o comportamento de interpretação dos pesquisadores/analistas do discurso, foi considerada como S-A com fontes de controle múltiplo (e.g., o texto do roteiro fornecido pela entrevistadora [textual], a questão em si mesma [mando], o encadeamento da própria escrita ou da fala encoberta da participante [intraverbal], dentre outras). Os elementos omissos das S-A's inferidos pelos pesquisadores/analistas foram escritos na discussão dos dados de modo a tornar as S-A's completas para a compreensão do leitor.

A resposta discriminativa dos pesquisadores/ analistas esteve sob controle das S-A's centrais e adicionais da participante. E as S-A's, por sua vez, estiveram sob controle das questões fornecidas pela entrevistadora e de regras advindas da religião que a participante seguia, regras essas inferidas do conteúdo das respostas escritas em consonância com as regras do catecismo da Igreja Católica (2006) e com a análise dos controles sobre a ação verbal dos pesquisadores, como leitores (Hayes \& Hayes, 1989). Após essas especificações as S-A’s foram submetidas às quatro etapas da hermenêutica comportamental, conforme descrito a seguir.

$\mathrm{Na}$ Etapa 1, os pesquisadores/analistas isolaram as S-A's realçando-as com uma cor no papel em que estavam impressas. Em seguida, os pesquisadores/ analistas, conforme sugerido por Skinner (1957), inferiram operantes essenciais (em geral, mas nem sempre, pelas topografias do tipo substantivo e imperativo), elos intraverbais (que sugeriam "temas") 
e modularam a intensidade, a energia e a velocidade da leitura de modo a inferir (da auto-observação da pertinência e dos controles de algumas das propriedades autoclíticas que acompanharam o seu próprio comportamento de interpretar) um conjunto de possíveis variáveis relacionadas ao discurso em análise.

Eventos antecedentes à S-A, como visto, podem ser alguma questão aversiva apresentada ou, até mesmo, alguma questão aversiva que o falante antecipa por supor que poderá ser apresentada (seja pela entrevistadora ou mesmo por um ouvinte genérico). A análise desses eventos antecedentes informou aos pesquisadores/analistas o que há além da "compreensão" da questão per se pela participante. Skinner (1957, p. 280) chamou isso de "artifícios de força" do comportamento verbal e eles puderam ser discriminados a partir do controle pela audiência do pesquisador/analista, inferido na Etapa 1. Ao intercalarem as funções de ouvintes e falantes, os pesquisadores/analistas modularam a leitura das $S$-A's de modo a evocar a resposta discriminativa da consequência do discurso da participante sobre o comportamento verbal deles próprios. Em geral, segundo Skinner, esses artifícios aumentam a probabilidade de que o discurso sob análise esteja repleto de recursos retóricos sofisticados, tais como ironia, sarcasmo, prolepse, antipófora, paralipse ou "frases felizes", que precisam ser considerados na ACD. Todos esses eventos antecedentes adquirem sua função a partir dos eventos consequentes que o discurso produz, em geral, reforços generalizados (por exemplo, compreensão ou concordância para um discurso "pronto", "esperado", "politicamente correto", "convencional" ou "bem sucedido").

$\mathrm{Na}$ Etapa 2, os pesquisadores/analistas realizaram um procedimento de análise que permitisse a evocação, em seu repertório verbal, de respostas discriminativas dos controles das S-A's: se elas se mantiveram ao longo do discurso, ou seja, se houve uma regularidade em uma ou mais funções por eles discriminadas. Diante de tal regularidade, na Etapa 3 , os pesquisadores/analistas inferiram os prováveis controles antecedentes e consequentes das S-A e as agruparam em classes a partir de funções comuns, como mandos, tatos etc. A Etapa 4 foi a autodescrição dos controles que evocaram os comportamentos verbais dos pesquisadores/analistas nas etapas anteriores. Por fim, as discriminações de cada um dos quatro pesquisadores/analistas do artigo foram corroboradas pelos demais.

\section{Resultados e discussão}

Como em qualquer texto escrito em resposta a entrevistas, as respostas da participante do presente estudo estiveram sob controle direto dos estímulos verbais visuais que constituem todas as respostas emitidas por ela (produtos de suas respostas verbais motoras) diante das questões da entrevista e de todas as questões da entrevista apresentadas a ela. Essas questões tiveram função de mando, à medida que direcionaram a ação da participante a responder de modo específico. Com função de mando, portanto, estiveram sob controle de uma operação estabelecedora - a ausência dos dados atuando sobre o comportamento da entrevistadora para cumprir o objetivo da pesquisa. Essa operação controlou a formulação das questões pela entrevistadora que, por sua vez, controlaram o responder da participante.

Uma questão "é um mando que especifica a ação verbal, e o comportamento do ouvinte permite-nos classificá-la como uma solicitação, uma ordem ou um pedido, conforme o caso" (Skinner, 1957, p. 39). No caso do presente estudo, os mandos-questões foram solicitações. Não importa qual seja o pronome inicial de uma questão (onde, qual, o que, quem...), o mando implícito genérico com um tom não impositor é diga. Por outro lado, mesmo que não impositor, qualquer mando-questão em entrevistas estabelece uma condição minimamente aversiva que altera a condição na qual se encontra aquele que responde (operação estabelecedora), de modo que a resposta dada por ele ao mando-questão também pode ter função de mando. Devido ao controle múltiplo, questões de entrevistas têm outras funções concomitantes. Nesse caso, o comportamento verbal da entrevistadora esteve sob controle (quando ela elaborou o roteiro) do contato com alguém com câncer e com fé, que evocou, por controle intraverbal, outros operantes relacionados ao mesmo tema. Antes mesmo da entrevista, o controle pela audiência atuou sobre o comportamento verbal do pesquisador/analista, evocando as questões componentes do roteiro, quando perguntou, no caso, "Quais perguntas so- 
bre fé se poderia fazer para alguém que está com câncer?" (ou, genericamente, "Quais respostas são necessárias ao problema de pesquisa?”).

$O$ responder à pergunta da entrevistadora esteve relacionado à história de reforço da participante em responder questões. O conteúdo do relato verbal da participante foi controlado por uma história de aprendizagem transmitida pela cultura, a qual ela pertence. A resposta verbal da participante esteve sob controle, também, de uma história de aprendizado da língua que ela e a entrevistadora compartilham. Assim, para a participante ter emitido um discurso produzido por suas respostas verbais motoras foi necessária uma história de aprendizagem da escrita em língua portuguesa.

A Figura 1 apresenta os elementos funcionais da S-A dada à primeira questão, analisados pela forma como a ACD foi conduzida, conforme descrita anteriormente, tendo como foco os efeitos do discurso sobre o interpretar. Sob controle do mando-questão emitido pela entrevistadora, a participante emitiu o argumento central $A$ fé é tudo encadeado intraverbalmente com dois argumentos adicionais emoldurados a partir do operante essencial fé: $A$ fé é o acreditar em... e A fé é a esperança de.... Há emissões de cadeias intraverbais idiossincraticamente condicionadas (Vargas, 1986), sob controle também da sinonímia de palavras, de fragmentos verbais (crença-crer-acreditar) e/ou da experiência em uma comunidade verbal religiosa (Deus-vidaesperança-melhores-aperfeiçoamento).

Parece haver um importante controle desses argumentos pela audiência da entrevistadora, uma variável raramente considerada na "análise de conteúdo" tradicional (Bardin, 1979): "para quem tem fé, todo aquele que a tem sabe (ou deveria saber) o que a fé representa" (essa regra é compartilhada entre os membros da comunidade verbal dos fiéis, da qual a participante parece supor pertencer o ouvinte/leitor; Pimentel, 2009). A modulação da leitura dos argumentos permite inferir uma ênfase na emissão verbal dos operantes, um "artifício de força” da função autoclítica que, sob controle da audiência, aumenta a probabilidade de serem mais precisos os efeitos dos operantes constitutivos dos argumentos acerca do que a fé representa para um fiel. A discriminação desses "artifícios de força" é importante na $\mathrm{ACD}$, pois, como dito, eles têm a função de alterar a força de um suposto comportamento do ouvinte.

Um recurso autoclítico primordial em um desses artifícios é a predicação. A predicação é combina um autoclítico qualificador (no caso, de asserção) com um relacional, ou seja, qualifica o operante verbal que produziu o registro visual-gráfico fé (que controla o comportamento textual dos pesqui-

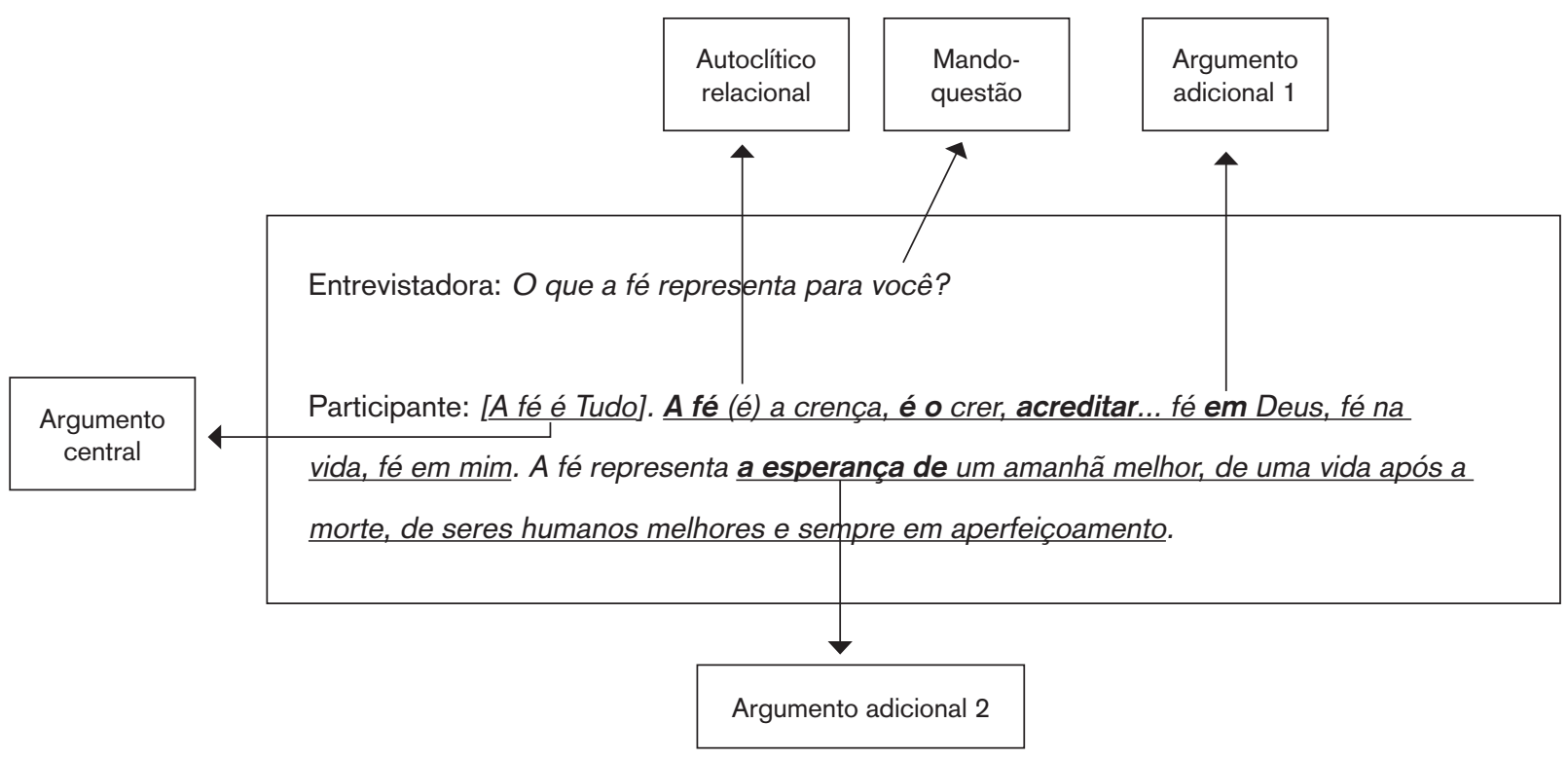

Figura 1. Elementos funcionais da sentença-argumento dada à primeira questão 
sadores/analista) a partir dos demais operantes aos quais está sendo relacionado (uma cadeia intraverbal): Deus-vida-mim-esperança-morte-humanos. A forma autoclítica de emissão dos argumentos a partir da predicação tem a função de torná-los parecidos com tatos (ou seja, "fortes"), uma estratégia retórica de convencimento do ouvinte (Guerin, 1994; Terrell \& Johnson, 1989; Borloti, 2003; Borloti et al., 2008). Todavia, funcionalmente, são intraverbais. Sente-se a diferença de força da crença, por exemplo, se o argumento central fosse emitido com funções intraverbais diretas: Eu ouvi na Igreja que a fé é tudo ou Eu li na Bíblia que a fé é tudo.

A segunda questão e resposta da entrevista estão especificadas na Figura 2, em que se observa que a resposta aos mandos-questões da entrevistadora contém um dos autoclíticos "artifícios de força" citados anteriormente. Parece que a participante objetivou produzir no repertório da entrevistadora uma resposta à questão, que é, de fato, o argumento central implícito na resposta. $\mathrm{O}$ argumento central Sei que se não tivesse fé, hoje não estaria mais viva (e do qual se infere uma afirmação à pergunta da entrevistadora) está suportando os dois argumentos adicionais explicitados como a resposta: Existe um
Ser Superior que coloca desafios ao nosso crescimento e Existe um Ser Superior que não é carrasco como muitas religiões impõem. Isso indica que a participante tateia a relação com a doença com o operante que gerou o registro visual-gráfico desafio; a doença tem a propriedade de algo a ser vencido.

O controle pela audiência atua sobre outros processos autoclíticos da exposição argumentativa aos mandos-questões. Primeiro, os operantes da resposta foram precedidos pelo tato do tempo presente da experiência com a doença (hoje) e que exerceu controle intraverbal para o tempo passado nessa mesma experiência (tivesse e estaria). Uma propriedade comparativa entre esses tempos controla a emissão do autoclítico descritivo Sei. O que ocorreu no passado é dito adiante, como resposta à terceira questão: Eu achava mesmo que não aguentaria e que iria morrer. Isso mostra a interdependência funcional entre S-A's (já ditas, sendo ditas e ainda por dizer) que fazem parte da retórica do falante e que controlam o seu discurso em andamento. Desse modo, o tato da propriedade temporal da experiência parece ser uma função fundamental no discurso sobre a influência da fé na experiência da participante com o câncer.

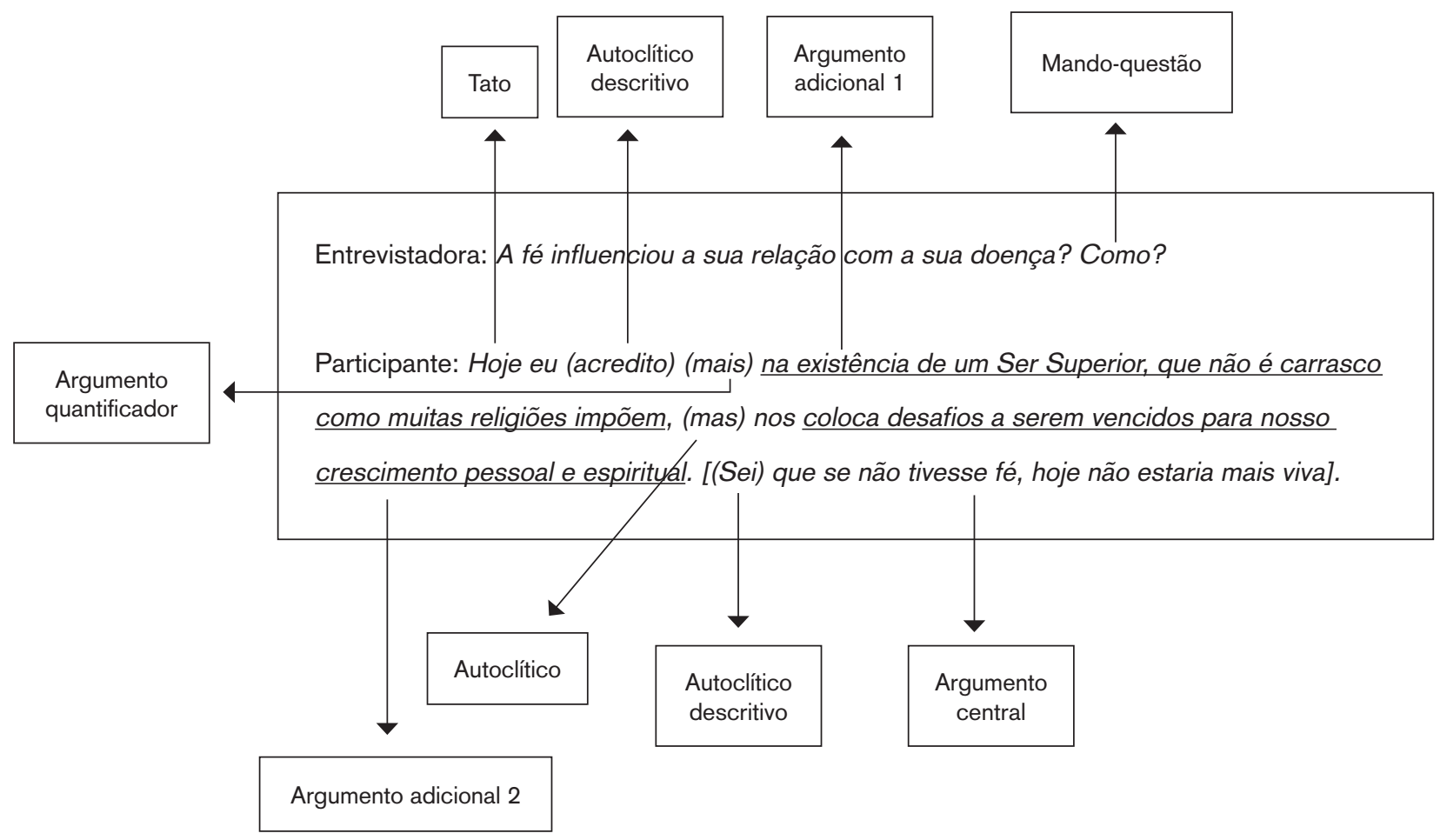

Figura 2. Elementos funcionais da sentença-argumento dada à segunda questão 
A participante inicia tateando as contingências atuais atuando sobre seu comportamento como sendo a sua própria crença, que é parte do seu repertório verbal. Depois, emite Acredito, um autoclítico descritivo, que tem a função de mostrar ao ouvinte as propriedades dos operantes essenciais intraverbalmente conectados (ser-superior-carrasco-religiões-desafios-crescimento-pessoa-espiritual-fé-viva) e as condições de sua emissão (de um falante crente que saíra de uma condição de descrente). É importante lembrar que para o crente, a modificação do operante existência pelo autoclítico em Eu acredito na existência busca apresentá-lo ao ouvinte como se fosse tato: Existe. Portanto, a unidade autoclítica Acredito é uma discriminação dos próprios comportamentos verbais do falante, controlados tanto por propriedades de contextos antecedentes passados de descrença quanto por propriedades do contexto atual de crença, que a participante informa ao ouvinte. No passado, no início da doença, a participante provavelmente informava ao ouvinte uma descrença (ou afirmações da improbabilidade) da existência de um Ser Superior benevolente (ver respostas à terceira questão adiante); no presente, ela informa ao ouvinte a crença da existência desse Ser. Isto é exacerbado na função do autoclítico quantificador mais, que "tateia" a propriedade quantidade das variáveis de controle do Acredito.

Outras propriedades "tateadas" por Acredito (não carrasco e desafiador) são as do operante que gerou o registro visual-gráfico Ser Superior e informam diretamente ao ouvinte o sentido intraverbal de Deus para a participante. As vírgulas que dividem o registro, a ênfase no não e no como muitas e a emissão do manipulativo mas informam a criação autoclítica de apresentar e contrapor dois elos intraverbais fundamentais à função do discurso: Ser Superior-coloca desafios e carrasco-religiões impóem. De novo, pelos critérios da ACD descritos anteriormente, tais elos parecem ter sido apresentados como se fossem tatos, dando impressão de terem como objetivo aumentar o poder de convencimento naquilo que é dito. Isso pode ser corroborado na função do mas, um autoclítico manipulativo que, sob controle das propriedades aversivas da tendência do comportamento do ouvinte (em tatear propriedade aversiva em Deus, como muitas pessoas tateiam), o instrui a rearranjar suas reações ao Ser
Superior (o operante essencial primordial da S-A) do modo julgado apropriado pela participante. Esse modo apropriado é indicado também na apresentação do elo intraverbal Ser Superior-coloca desafios como se fosse um tato. O mas, sendo um autoclítico "de mando", impele o ouvinte a abandonar uma construção verbal de Deus (a partir do operante carrasco) em prol de outra com os seguintes elos intraverbais (emitidos como tatos): coloca-desafios-vencidos-crescimento-pessoal-espiritual. Disso se infere uma atitude imiscuída com uma crença diante do câncer. Segundo Guerin (1994), apesar de os psicólogos sociais tratarem a atitude como uma expressão de preferência e a crença como uma expressão de resultado, fica clara a fusão de ambas e a impossibilidade de separá-las no discurso da participante, uma vez que cada uma dessas expressões verbais "é contingentemente modelada pela comunidade de ouvintes" (p. 160). Ao se atentar sobre as funções da retórica da participante, infere-se que sua crença, como se fosse tato, é emitida como uma atitude consistentemente reforçada pela sua comunidade verbal: Sei que se não tivesse fé, hoje não estaria mais viva. A suposta explicação comportamental desse arranjo discursivo é que:

Crenças que são apresentadas na forma de atitudes são reforçadas com mais frequência, e atitudes ou crenças intraverbais que são apresentadas na forma de tatos são reforçados com mais frequência. Os efeitos sobre um ouvinte podem ser modificados ainda mais se atitudes, em vez de crenças sobre os resultados, são afirmadas, e se ambas, atitudes e crenças, puderem ser apresentadas como tatos em vez de intraverbais. (Guerin, 1994, p. 160).

Isso é demonstrado pela entonação indicada pelo ponto que antecede a afirmação da crença-atitude diante do câncer e pela vírgula que a divide. A continuidade do relato com a regularidade das funções apresentadas antes parece novamente aumentar o poder de convencimento na crença-atitude. Com a função de modificar a intensidade ou a direção do comportamento do ouvinte quanto aos operantes essenciais fé e viva da S-A, os autoclíticos de negação, de quantificação e os tempos verbais em não tivesse e não estaria mais, denota que fé e viva podem ter sido 
emitidos como tatos. $\mathrm{O}$ fato de a participante fazer parte de uma comunidade verbal religiosa traz uma particularidade a sua fala: Sei (um autoclítico "de tato" que descreve ao ouvinte as condições de emissão dos operantes essenciais fé e viva). Ele informa diretamente ao ouvinte sobre a força do controle do estímulo visual-gráfico fé, dada pelo intraverbal na forma de tato, e como os operantes da crença-atitude diante do câncer se relacionam.

A terceira questão e resposta da entrevista estão especificadas na Figura 3. Nessa resposta, a participante descreve melhor como a fé influenciou a vida dela a partir da doença. Em continuidade à argumentação apresentada na questão anterior pela participante, ela retoma elos temáticos intraverbais, envolvendo o operante verbal Deus e enfatiza propriedades do contexto de estímulos que permitem descrever o que Deus é e não é. O argumento central apresentado é: Deus não nos impõe as coisas como castigo. Os adicionais são: Não creio mais nisso. Acho que todos temos algo a aprender nessa vida e são nesses piores momentos que aprendemos como somos fortes e como podemos nos tornar melhores e ajudar a outros que ainda estão piores que nós. Há elementos autoclíticos fundamentais à junção dos argumentos adicionais ao central: o mas, o não, o creio, a inflexão de toda a sentença Não creio mais nisso, as unidades de tempo e o acho.

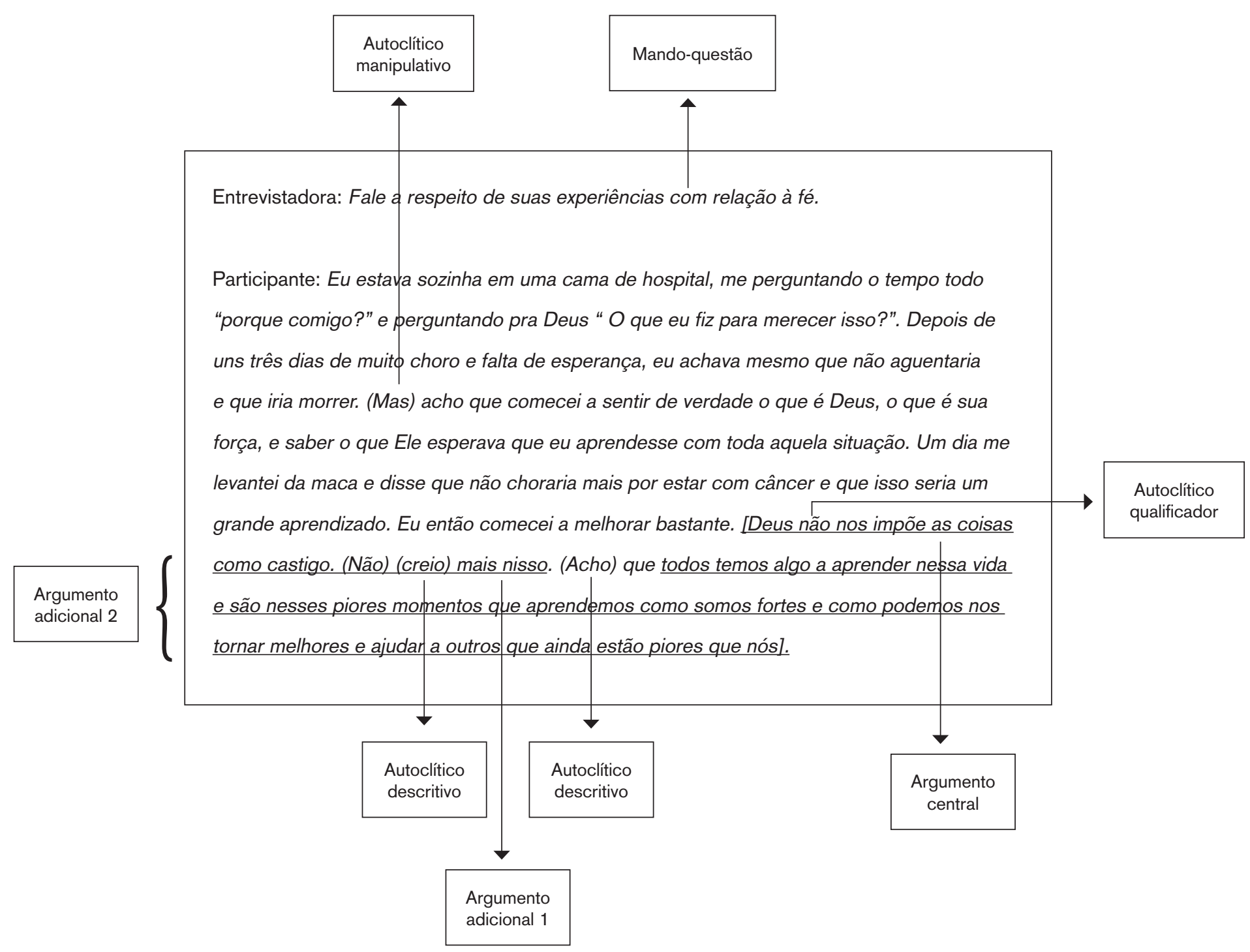

Figura 3. Elementos funcionais da sentença-argumento dada à terceira questão 
A regularidade das funções verbais de alguns dos trechos anteriores permite inferir a função autoclítica manipulativa combinada com a qualificadora de negação e com a descritiva. A negação está sob controle das propriedades relativas à qualidade que acompanham o operante que produziu o registro Deus. A função autoclítica da negação é modificar a direção do comportamento do ouvinte, de "tatear" uma qualidade carrasca que poderia acompanhar a emissão do operante Deus no repertório dele, o ouvinte. O manipulativo mas e a inflexão de Não creio mais nisso, sob controle da aversividade dessa direção, impelem o ouvinte a abandonar uma construção verbal na qual Deus teria essa propriedade e rearranjar seus operantes do modo julgado apropriado pela participante. E esse modo apropriado informa as propriedades de verdade do operante essencial Deus. O Creio, como registro de um autoclítico descritivo, tem a função de informar ao ouvinte essas propriedades e a condição em que esse operante (Deus) é emitido pela participante a partir das demais molduras autoclíticas funcionalmente unificadas. A inflexão fortalece essa unificação.

Observa-se a função autoclítica do tempo verbal e de outras unidades temporais e descritivas no auxílio à função manipulativa no seguinte encadeamento que sintetiza a experiência da participante com a fé: estava-depois-achava-[um]dia-levantei-então-comecei. Isso permite levantar a hipótese de que o acho, como autoclítico descritivo, está sob controle da intensidade do operante essencial Deus, informando o estado de força de sua emissão. No caso, ao se empregar o método da ACD, a entonação de Acho que comecei a sentir de verdade o que é Deus indica que não há dúvidas no tato das propriedades dos estímulos que evocam a emissão de Deus; e acho, portanto, pode ter tido a mesma função de creio. A discriminação de uma regularidade nessa interpretação pode ser vista adiante quando a entonação de Não creio mais nisso permite que a próxima S-A seja Creio que todos temos algo a aprender nessa vida. De novo, intraverbais são apresentados como se fossem tatos e a crença definidora da fé é emitida como atitude.

Todo comportamento verbal é controlado por variáveis antecedentes e selecionado e mantido por variáveis consequentes. $\mathrm{O}$ próprio comportamento de descrever funcionalmente o analisar é um exem- plo disso, pois a análise que foi realizada, também deverá controlar os comportamentos do leitor, concernentes ao contexto deste trabalho verbal. Assim, para finalizar, seguem algumas observações sobre o controle da interpretação, a Etapa 4 da ACD: por que a interpretação lida até então foi possível?

Os comportamentos dos pesquisadores/analistas, ao inferirem as relações verbais unificadas no discurso, estavam sob controle das regras que definem tais relações, de acordo com Skinner (1957), e das propriedades do texto da participante, inferidas do comportamento verbal dos pesquisadores/analistas, sob controle do produto do comportamento dela (o texto). De fato, a interpretação posta até agora neste artigo não esteve sob controle direto do comportamento da participante, mas dos efeitos que o produto do comportamento dela teve sobre os comportamentos dos pesquisadores/analistas. Portanto, a análise do discurso da participante foi evocada na auto-observação do comportamento verbal dos pesquisadores/analistas ao discriminarem o objetivo do discurso, ou seja, ao observar ou inferir os antecedentes e consequentes às S-A's.

As regras de classificação funcional do comportamento que gerou o registro verbal (Skinner, 1957) guiaram o comportamento dos pesquisadores/analistas ao fazer tais observações/inferências a partir da compreensão de funções. Nisso, eles tiveram que considerar as variáveis que poderiam ter controlado o discurso e que puderam ser discriminadas a partir dos efeitos do registro verbal sobre o comportamento de interpretar dos pesquisadores/analistas. Posicionados como ouvintes, os pesquisadores/analistas puderam observar/inferir, dessa forma, as variáveis relacionadas à relação falante-ouvinte que podem ter atuado na história de vida da participante no enfrentamento do câncer a partir da religião. Dessa forma, foi possível apontar uma regularidade das classes funcionais operantes verbais analisadas em função dos efeitos que sua conjugação no discurso exerceram sobre o comportamento verbal de interpretar dos pesquisadores/ analistas. As respostas funcionalmente unificadas no discurso conjugaram a função de mando, tato e intraverbal.

A função intraverbal foi a mais evidente devido ao controle temático evocado pelas questões; e, para um melhor controle da compreensão e do con- 
vencimento da audiência, foi emitida como se tivesse função de tato. Entretanto, como especificado anteriormente, respostas em entrevistas estão sob controle aversivo e, portanto, também podem ter tido função de mando, que poderia ser resumido assim: "Acredite no que eu estou lhe respondendo". Essa função é atrelada à S-A central (Sei que se não tivesse fé, hoje não estaria mais viva) e a dois operantes essenciais, também inter-relacionados (fé e Deus). Operantes essenciais e S-A's central e adicionais, estão funcionalmente unificadas por unidades autoclíticas descritivas (acredito, creio, acho) manipulativas (mas, inflexão, pontuação), negação (não) e predicação (é). Portanto, a interação social mantida pelo discurso da participante foi marcada pelo objetivo de convencimento do ouvinte nas propriedades positivas da experiência com a doença.

Dada às múltiplas funções, o comportamento verbal dos autores ao produzir este texto foi influenciado também por estimulação anterior (e.g., leituras sobre comportamento verbal, câncer e religião, experiências clínicas com portadores dessa doença, aspectos do idioma português e da história de aprendizado de respostas verbais motoras de escrita) e atual (e.g., a função discriminativa das palavras produzidas como consequência de digitar, possíveis consequências reforçadoras ou punitivas e condições de motivação em função delas e pelos efeitos que poderiam produzir no leitor deste artigo). Assim, o comportamento verbal cujo produto foi lido pelo leitor pode ser considerado o resultado conjunto de estimulação para intraverbais, tatos, mandos, textuais e autoclíticos.

\section{Conclusão}

Uma conclusão foi obtida quando se analisou o próprio analisar as regularidades das classes funcionais do discurso, como exposto anteriormente. Vê-se, assim, que a ACD é uma abordagem de aproximação da Análise do Comportamento aos métodos de pesquisa qualitativa, por exemplo, dentre tantos, a análise de conteúdo (Bardin, 1979). Seus pressupostos permitem compreender a variação e a permanência do discurso, bem como a que tipo de audiência interessa variar ou permanecer.

Realizar uma ACD é um trabalho que apresenta dificuldades, pois é complexo identificar a função dos operantes que compõem o discurso, uma vez que estão sob controle múltiplo. A essa dificuldade se soma o acesso limitado às variáveis de controle. Quando se analisa o produto do comportamento verbal (no caso deste estudo, o registro escrito gerado por ele) o acesso às variáveis de controle presentes no momento da emissão da resposta se torna inviável, assim como o acesso à história de reforço que instalou tal repertório, restando ao pesquisador/analista, segundo Skinner (1957), apenas a possibilidade de analisar os efeitos desse registro sobre seu próprio repertório verbal. Devido a essa limitação inexorável, verificar as fontes de controle que estão atuando sobre uma relação verbal componente do discurso implica levantar o máximo de variáveis antecedentes e consequentes que poderiam ter feito parte dessa relação, incluindo as suas operações estabelecedoras. Essa tarefa torna-se mais complexa na terceira e quarta etapas da $\mathrm{ACD}$, quando a própria analise é analisada, pois é nelas que o analista passa a discriminar-se em vários papéis (intérprete, falante, ouvinte, escritor e leitor).

Portanto, a ACD é um exercício interpretativo que desafia o próprio analista e, ao mesmo tempo, uma resposta behaviorista radical à análise qualitativa de dados verbais per se. À medida que o analista passa para a terceira etapa desse exercício, ele começa a analisar o seu próprio comportamento verbal, que é controlado tanto pelo relato analisado quanto pela sua formação. O analista observa que as suas respostas verbais são controladas pelo produto verbal do relato analisado, pelas leituras anteriormente realizadas, pelo seu contexto e sua própria história fundidos no trabalho verbal executado pelos vários papéis mencionados. $\mathrm{E}$, dessa forma, com muitas variáveis controlando o seu comportamento, o analista faz sua interpretação; e ao fazer sua interpretação, lança um novo trabalho de validação da interpretação destinado aos leitores. Realizar a ACD permite inferir a reação do leitor ao discurso (texto), a partir dos processos que podem aumentar a probabilidade de um discurso (texto) vir a acontecer adiante, no repertório do analista ou do leitor, numa tarefa desconstrucionista. Parafraseando Vargas (1992), se você, leitor, compreendeu o significado do texto deste artigo, isso ocorreu apenas quando compreendeu os controles sobre seu próprio comportamento nos mes- 
mos pontos onde esses controles se fundiram aos controles que operaram este texto, corroborado por todos os autores que, concomitantemente, também foram leitores.

\section{Referências}

Abreu, A. S. (2009). A arte de argumentar: Gerenciando razão e emoção. São Paulo: Ateliê.

Bardin, L. (1979). Análise de conteúdo. Lisboa: Persona.

Borloti, E. (2003). O discurso de Skinner: uma análise funcional do citar no Verbal Behavior (Tese de Doutorado). Pontifícia Universidade Católica de São Paulo, São Paulo, SP.

Borloti, E., Iglesias, A., Dalvi, C. M., \& Silva, R. D. M. (2008). Análise comportamental do discurso: fundamentos e método. Psicologia: Teoria e Pesquisa, 24, 101-110. doi: org/10.1590/S010237722008000100012

Catania, A. C. (1998). The taxonomy of verbal behavior. In K. A. Lattal \& M. Perone (Orgs.), Handbook of research methods in human operant behavior (pp. 405-433). New York: Plenum.

Dougher, M. J. (1993). Interpretative and hermeneutic research methods in the contextualistic analysis of verbal behavior. In S. C. Hayes, L. J. Hayes, H. W. Reese, \& T. S. Sarbin (Orgs.), The varieties of scientific contextualism (pp. 147159). Reno: Context.

Foucault, M. (1973). A ordem do discurso. (S. Possenti, Trad.). Ijuí: Fidene. Publicado originalmente em 1971.

Glenn, S. S. (1989). Verbal behavior and cultural practices. Behavior Analysis and Social Action, 7, 10-15.

Gill, R. (2002). Análise de Discurso. In M. W. Bauer \& G. Gaskell (Orgs.), Pesquisa qualitativa com texto, imagem e som: um manual prático (3a ed., pp. 244-70). Petrópolis, RJ: Vozes.

Gracia, T. I. (2004). O "giro linguístico". In L. Iñiguez (Org.), Manual de análise do discurso em Ciências Sociais (pp. 19-49). Petrópolis: Vozes.

Guerin, B. (1992). Behavior analysis and the social construction of knowledge. American Psychologist, 47, 1423-1432. doi:10.1037/0003-066X.47.11.1423
Guerin, B. (1994). Attitudes and beliefs as verbal behavior. The Behavior Analyst, 17, 155-163.

Hayes, S. C, \& Hayes, L. H. (1989). The verbal action of the listener as a basis for rule-governance. In S. C. Hayes (Org.), Rule-governed behavior, cognition, contingencies, and instructional control (pp. 154-190). New York: Plenum.

O catecismo da Igreja Católica (2006). São Paulo: Canção Nova.

Passos, M. L. R. F. (2003). A análise funcional do comportamento verbal em Verbal Behavior (1957) de B. F. Skinner. Revista Brasileira de Terapia Comportamental e Cognitiva, 5, 195213.

Peterson, N. (1978). An introduction to verbal behavior. Grand Rapids, MI: Behavior Associates, Inc.

Pimentel, F. de C. (2009). Bem ditos e mal ditos em debates religiosos: uma análise funcional da auto-edição do comportamento verbal. (Dissertação de Mestrado não publicada). Universidade Federal do Espírito Santo, Vitória.

Place, U. T. (1998). Sentence and sentence structure in the analysis of verbal behavior. The Analysis of Verbal Behavior, 15, 131-133.

Reese, H. W. (1989). Rules and rule-governance: Cognitive and behavioristic views. In S. C. Hayes (Org.), Rule-governed behavior: Cognition, contingencies, and instructional control (pp. 3-84). New York: Plenum.

Saquetto, D., \& Borloti, E. (2008). Hermenêutica Comportamental. In W. C. M. P. Silva (Org.), Sobre comportamento e cognição: reflexões epistemológicas e conceituais, considerações metodológicas, relatos de pesquisa (pp. 45-54). Santo André: ESETec.

Skinner, B. F. (1957). Verbal Behavior. New York: Appleton- Century, Crofts.

Skinner, B. F. (1986). The evolution of verbal behavior. Journal of the Experimental Analysis of Behavior, 41, 217-222. doi: 10.1901/ jeab.1986.45-115

Skinner, B.F. (1987). Upon Further Reflection. Englewood Cliffs, NJ: Prentice- Hall.

Terrell, D., \& Johnston, J. M. (1989). Logic, reasoning, and verbal behavior. The Behavior Analyst, 12, 35-44. 
Vargas, E. A. (1986). Intraverbal behavior. In P. N. Chase \& L. J. Parrot (Orgs.), Psychological aspects of language (pp. 128-151). Springfield: ILL.

Vargas, E. A. (1992). Introduction II. In B. F. Skinner (Org.), Verbal behavior (pp. xiii-xxv). Acton: B. F. Skinner Foundation, Copley.

Informações do Artigo

Histórico do artigo:

Submetido em: 20/04/2013

Primeira decisão editorial: 16/06/2013

Segunda decisão editorial: 24/06/2013

Aceito em: 02/07/2013 